This is an electronic reprint of the original article. This reprint may differ from the original in pagination and typographic detail.

Author(s): Eyvindson, Kyle; Repo, Anna; Burgas Riera, Daniel; Mönkkönen, Mikko

Title: $\quad$ Landowner preferences and conservation prioritization : response to Nielsen et al

Year: $\quad 2017$

Version:

Please cite the original version:

Eyvindson, K., Repo, A., Burgas Riera, D., \& Mönkkönen, M. (2017). Landowner preferences and conservation prioritization : response to Nielsen et al. Conservation Biology, 31(6), 1488-1490. https://doi.org/10.1111/cobi.13004

All material supplied via JYX is protected by copyright and other intellectual property rights, and duplication or sale of all or part of any of the repository collections is not permitted, except that material may be duplicated by you for your research use or educational purposes in electronic or print form. You must obtain permission for any other use. Electronic or print copies may not be offered, whether for sale or otherwise to anyone who is not an authorised user. 


\section{Landowner preferences and conservation prioritization: response to Nielsen et al.}

\section{Authors mailing addresses:}

Kyle Eyvindson $^{1 *}$, Anna Repo $^{1,2}$, Daniel Burgas ${ }^{1,3}$, Mikko Mönkkönen $^{1}$

${ }^{1}$ University of Jyvaskyla, Department of Biological and Environmental Science, P.O. Box 35, 40014 University of Jyvaskyla, Jyvaskyla, Finland

${ }^{2}$ Finnish Environment Institute, Climate Change Programme, Mechelininkatu 34a, P.O.Box 140, FI-00251 Helsinki, Finland

${ }^{3}$ Department of Forest Sciences, P.O. Box 27, 00014 University of Helsinki, Finland *email kyle.j.eyvindson@jyu.fi,

Running head: Conservation prioritization

Keywords: integer programming, spatial resolution, conservation budgeting, spatial prioritization, voluntary conservation

Article impact statement: Incorporating landowner preferences in prioritization schemes may not improve conservation efficiency.

This is the accepted version of the following article:

Eyvindson, K., Repo, A., Burgas, D., M önkkönen, M. 2017. Landowner preferences and conservation prioritization: response to Nielsen et al. Conservation Biology. doi: 10.1111/cobi.13004, which has been published in final form at doi.wiley.com/10.1111/cobi.13004. This article may be used for noncommercial purposes in accordance with the Wiley Self-Archiving Policy. 
In a recent article Nielsen et al. (2017) concluded that knowledge of landowner preferences related to conservation can provide substantial gains in conservation efficiency. They contend the efficiency gain is especially large when conservation budgets are limited. Nielsen et al. combined actual landowner participation in voluntary conservation and species occurrence data sets in a unique way, which could be highly beneficial for the planned use of funding for conservation efforts. Through their analysis, Nielsen et al. suggest that inclusion of landowner preferences will always benefit conservation even though habitat fragmentation increases and the potential area available for conservation decreases when landowner preferences are considered. Although we see considerable merit in their work, we question this optimistic result obtained by integrating landowner preferences in conservation prioritizations and believe that the efficiency gain is at least partly due to artefacts created through their modeling process. We think that 2 modeling errors cause this optimistic result.

One issue is how they used the species-persistence probability model. This model has 2 components, occurrence and long-term survival of species. In the model Nielsen et al. formulate, $\left(p_{i j}=\xi_{i j}\left(a_{j}\right) \gamma\left(a_{j}\right)\right.$, where $\xi_{i j}\left(a_{j}\right)$ is the probability of species $i$ occupying cell $j$ and $\gamma\left(a_{j}\right)$ is the long-term-survival probability function), the conserved area $\left(a_{j}\right)$ plays a key role in both estimating the species occurrence and in evaluating long-term survival. However, the importance of a change in the area conserved differs dramatically depending on whether one is estimating occurrence probability or long-term survival probability. Nielsen et al. modeled occurrence probability based on total forest area, broadleaved tree coverage, area of unmanaged forest, and a regional dummy variable. The long-term survival probability is modeled using 2 Gompertz functions: a sigmoidal response in survival probability with forest area set aside and an approximately linear function assuming a smooth linear response in survival probability to forest 
area set aside. The predictive variable for both survival probability functions is the area of forest set aside. This assumes the amount of forest set aside has a great effect on species long-term survival. Regardless of the survival-probability model selected, the optimization model includes an implicit assumption that if no area is conserved in a particular cell, then there will be a $0 \%$ probability of any species surviving. This assumption ignores the remaining ecological value of intensively used forests, and it is likely to bias the results. Alternative optimization models could be developed that include the ecological value of these intensively used forests.

The second issue is use of the integer programing model to compare the uninformed (entire forest area of a cell is conserved) and informed (only the expected forest area available for conservation in a cell is conserved) cases. The specific model used is a $0-1$ integer-programing model in which the decisions are binary, either conserve a specific area or not. Nielsen et al.'s model is an extension of the model developed by Arthur et al. (2004). Arthur et al.'s (2004) objective is to maximize the expected number of species conserved and to maximize the likelihood of representation of a subset of endangered species under a set budget constraint (which ensures that the total costs for each scenario are comparable). Arthur et al.'s (2004) results revealed a trade-off between budget and species conservation. The model developed by Nielsen et al. extends these ideas by examining the difference in conserving the entire forest area in a cell or conserving only the expected area supplied by private landowners. However, because the costs of conservation are related to the areal extent and specific environmental and economic conditions of sites (the cost of conserving an uninformed cell will be higher than the cost of conserving an informed cell), a direct comparison between cases may not be appropriate.

Although the difference in conservation potential between the uninformed and informed cases may appear logical, the justification for applying Arthur et al.'s (2004) integer programing model 
in this case is questionable. If one can adjust the proportion of land available for conservation in each cell, what is the justification for conserving all land in a particular cell and the requirement of integer programing? If the use of integer programming is justifiable, a second question related to comparability arises. When comparing optimization models, care must be taken to ensure that each component of the model is properly understood and correctly used (Hillier \& Lieberman 2000). In this case, integrating the potential area available for conservation purposes affects the spatial features of the model.

The approach Nielsen et al. applied appears to allow a change in the spatial resolution of the cells (i.e., if 2,500 $\mathrm{m}^{2}$ of a cell is forested [the uninformed case] and landowner willingness for conservation is $1,000 \mathrm{~m}^{2}$ ). This is problematic because the shift is always toward increased resolution for the informed case, the informed case is operating with increased spatial resolution, and the informed case can be used to more efficiently allocate resources. Therefore, the efficiency gain of the informed scenario stems from higher spatial resolution of data and from the integer programming model rather than directly from the use of landowner information. An increase in spatial resolution without information on landowner's willingness to participate may also result in greater efficiency.

To explore this issue in more detail, we applied a hypothetical data set to the models. The methods we used to simulate the data and to reproduce the results from Nielsen et al. are in Supporting Information. As in Nielsen et al., our results with simulated data also showed that with intermediate budgets the difference between the informed and uninformed cases was rather high and this difference deceased as the conservation budget increased (Supporting Information). 
Allowing differences in the area available for conservation in the uninformed and informed scenarios directly affected the cost of conservation and the species' persistence probability. We accounted for persistence probability by using a model that incorporated the current probability of a species' presence and the long-term species' survival probability. As such, a decrease in the area conserved resulted in a linear decrease in costs, and the species' persistence probability decreased according to the function used for modeling the long-term survival probability. Were we to use a linear programing model, a proportion of the land within the cells with the highest conservation value would have been selected to efficiently allocate the budget. When we used an integer programing model, a cell could be either protected or not protected, and the budget played a key role in determining which cells could potentially be selected. For instance, with a budget of DKK150,000, only cells with $<85$ ha of forest available for conservation (if the per hectare cost is DKK1765/year) had the potential to be selected for conservation. By reducing the available area for conservation within the cells, the integer programing model was fundamentally changed because those cells became more affordable for conservation. This increased the decision space and allowed for a higher number of cells to be protected at a similar budget level. Although the cost of protecting these cells was linearly lower for the informed scenario than for the uninformed scenario, the conservation value decreased in a nonlinear fashion (depending on the survival function chosen).

By systematically reducing the area available for conservation in the informed case, the optimization model had more flexibility in selecting cells that provided more conservation value for the same budget. This can be seen as a general increase in the area protected and the total number of cells protected for the sigmoid survival curve and as a dramatic increase in the total number of cells protected at a cost of the area protected for the approximate linear survival curve 
(Fig. 1). When budgets were small (i.e., <DKK50 million) a very limited set of cells was conserved. For the sigmoidal case a similar number of cells were protected regardless of budgets (Fig. 1c), and for the approximate linear case as the budget increases, there is a quick increase in the number of cells were protected (Fig. 1d). For the sigmoid survival curve, a decrease in the potential conservation area (moving from the uninformed to informed cases) shifted the cost for conserving each cell along the curve. Because those cells with large potential areas available for conservation have a high species occurrence, a decrease of forest area available for conservation will impact the cost of conservation to a greater extent than the decrease in the long-term survival probability (as long as the area for conservation remains above the inflection point of the Gompertz function). When the linear approximation was used, a decrease in forest area available for conservation affected both long-term survival probability and cost similarly. However, with the same budget, a greater number of cells was protected when the available area for conservation decreased (Fig. 1d). Thus, the informed scenario was more cost-efficient than the uninformed scenario due to the lower costs of protecting each cell and the potential bias in the prediction of species occurrence. This result suggests that a direct comparison of the optimization results between uninformed and informed scenarios should be avoided.

The issues addressed by Nielsen et al. are of critical importance, and focusing on the use of landowner preferences for protection as a means to maximize species protection at a specific budget can aid in conservation efforts. With the data and tools they describe, a spatial optimization model could be developed that prioritizes the conservation benefit of each forest holding. Alternatively, the problem could be used to assess the conservation value lost due to the unwillingness of landowners to participate in conservation schemes. The costs of implementing a conservation policy involve more than simply the cost of setting aside land. Private ownership 
complicates protection efforts because the most valuable land for conservation may not be available for protection due to a landowner's preferences. The landowner-preference models and species' presence and survival models of Nielsen et al. will likely be valuable in lowering the costs of finding landowners that are interested in conservation who also have land with a high conservation value. To understand how conservation choices affect species persistence will require a shift in the optimization model, allowing for more flexibility to select specific forests to conserve (e.g., mixed-integer linear programing), and viewing forest conservation as promoting forest species persistence but not as the primary driver of persistence of forest species.

\section{Acknowledgments}

We are grateful to the Academy of Finland (project number 275329) for funding.

\section{Supporting Information}

The materials and methods to replicate this analysis (Appendix S1)is available online. The authors are solely responsible for the content and functionality of these materials. Queries (other than absence of the material) should be directed to the corresponding author.

\section{Literature Cited}

Arthur JL, Camm JD, Haight RG, Montgomery CA, Polasky S. 2004. Weighing conservation objectives: maximum expected coverage versus endangered species protection. Ecological Applications 14: 1936-1945.

Hillier FS, Lieberman GH. 2000. Introduction to operations research. Seventh edition. McGraw Hill. New York. 
Nielsen ASE, Strange N, Bruun HH, Jacobsen JB. 2017. Effects of preference heterogeneity among landowners on spatial conservation prioritization. Conservation Biology. 31(3): $675-685$ 
Sigmoidal
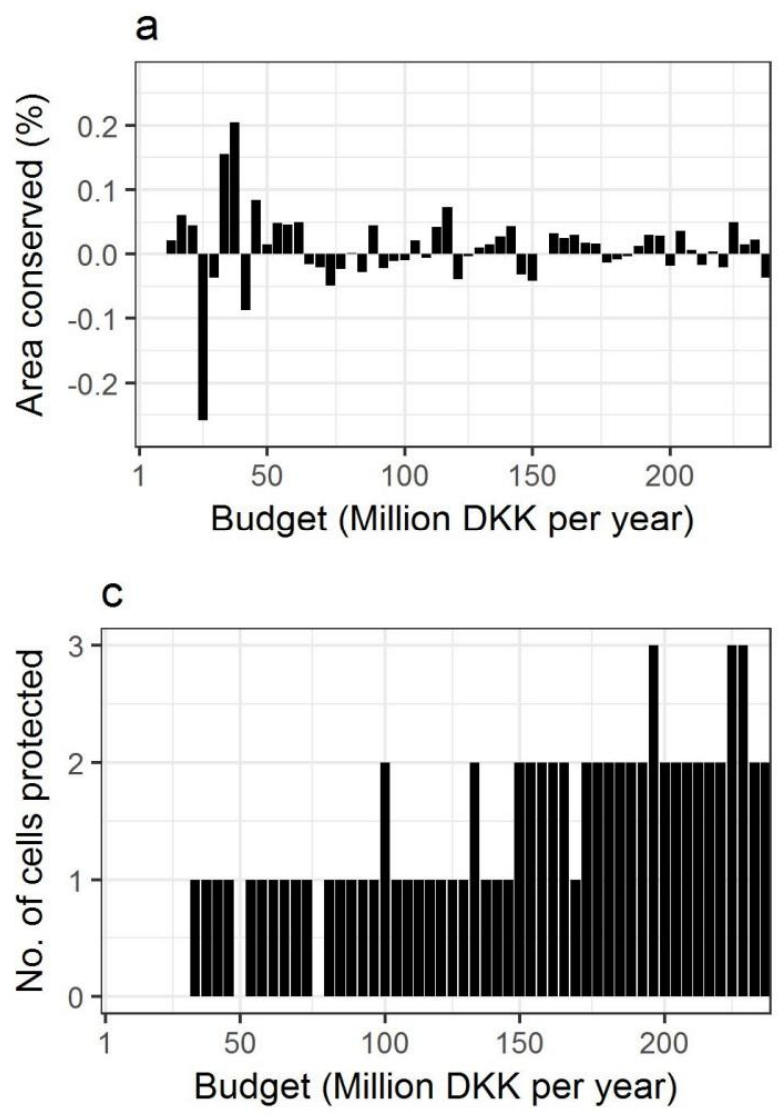
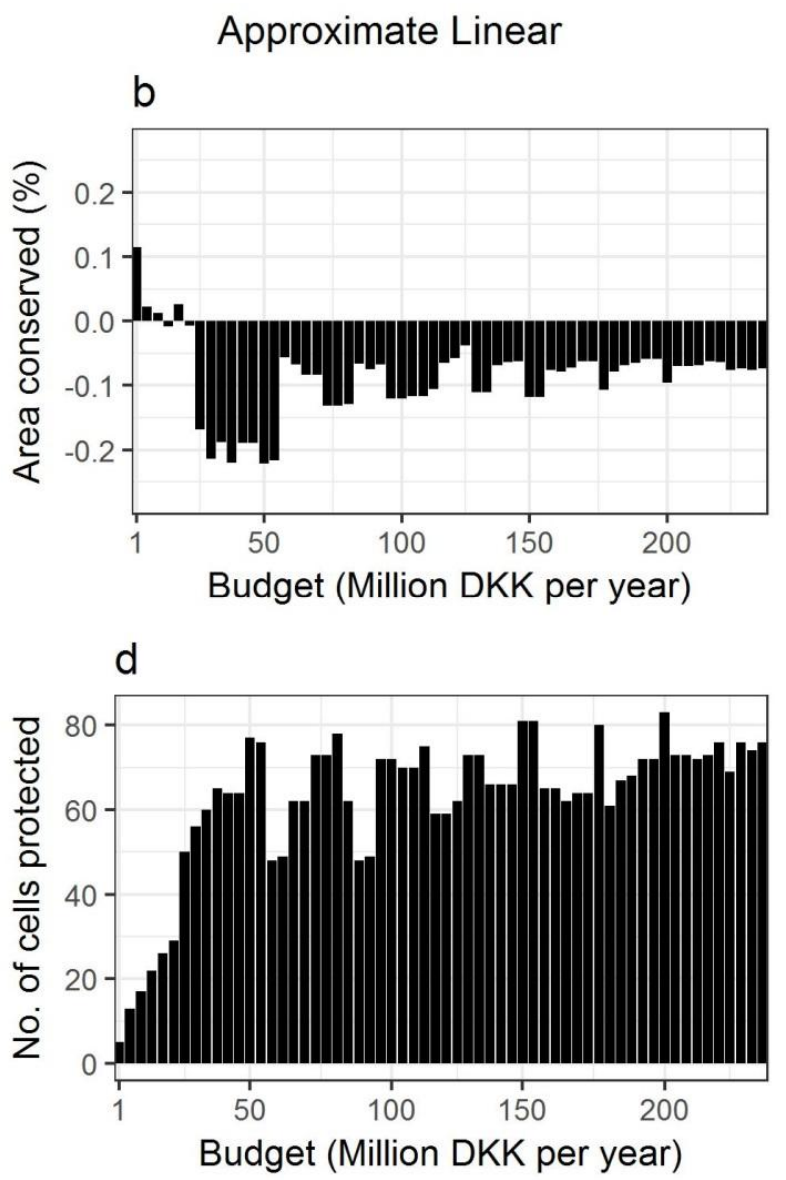

Figure 1. The difference between the informed and uninformed cases in $(a, b)$ the area conserved along a continuum of budget possibilities (positive values, benefit of incorporating landowner preferences [i.e., informed scenario]) and (c,d) the number of additional cells protected in the informed scenario relative to the uninformed scenario. The y-axis scales differ, which highlights the dependence of the conservation strategy on how the long-term survival probability is modeled. 